\title{
Seasonal and Geographic Variation in Condition of Juvenile Walleye Pollock in the Western Gulf of Alaska
}

\author{
ANDRE BuchHEISTER* \\ Department of Fisheries Science, Virginia Institute of Marine Science, College of William and Mary, \\ Post Office Box 1346, Gloucester Point, Virginia 23062, USA \\ Matthew T. Wilson \\ National Oceanic and Atmospheric Administration, National Marine Fisheries Service, \\ Alaska Fisheries Science Center, 7600 Sand Point Way NE, Seattle, Washington 98115, USA \\ ROBERT J. Foy \\ Fishery Industrial Technology Center, School of Fisheries and Ocean Sciences, \\ University of Alaska-Fairbanks, 118 Trident Way, Kodiak, Alaska 99615, USA
}

\section{David A. Beauchamp}

U.S. Geological Survey, Washington Cooperative Fish and Wildlife Research Unit, University of Washington, School of Aquatic and Fisheries Sciences, Post Office Box 355020, Seattle, Washington 98195, USA

\begin{abstract}
Body length, length-specific weight, and length-specific whole-body energy content (WBEC) of juvenile walleye pollock Theragra chalcogramma were examined for evidence of seasonal and geographic variation. Identifying the impact of winter on these measures of fish condition was of primary concern, but we also sought to determine whether condition varies among different geographic regions. The 2000 year-class of walleye pollock was sampled in the western Gulf of Alaska during four seasons (the autumn of 2000 and the winter, summer, and autumn of 2001), and the study area was divided into three regions (Kodiak, Semidi, and Shumagin). In each region, length-specific weight decreased from autumn to winter by up to $17 \%$, subsequently increasing into the summer by $13-20 \%$. Significant seasonal changes in length-specific WBEC varied by region but reflected the same trends as length-specific weight. Walleye pollock from the Kodiak region were in better condition than those from other regions, as evidenced by larger lengths in winter (18-mm difference) and summer, a 5.9\% higher length-specific weight in autumn of 2000, and higher length-specific WBEC in autumn of $2000(0.783 \mathrm{~kJ} / \mathrm{g}$ wet weight, or $18.3 \%$, higher $)$ and in the following winter $(0.607 \mathrm{~kJ} / \mathrm{g}$, or $14.1 \%$, higher). The poorer condition of juvenile walleye pollock in winter may be widespread through the Gulf of Alaska, but spatial heterogeneity in habitat can also greatly influence the size and condition of juveniles. The impact of such variability on growth and mortality remains uncertain.
\end{abstract}

Seasonal variation in productivity and water temperature largely determines the reproductive strategy and growth schedule of fish in temperate marine environments (Pitcher and Hart 1982). In these waters, spawning usually occurs during spring so that young fish are maximally exposed to periods of abundant food and warmer temperatures conducive to rapid growth (match-mismatch hypothesis; Cushing 1990). With the onset of winter, fish growth slows, energy reserves may be depleted, and juvenile mortality rates can increase (Sogard 1997; Hurst and Conover 1998; Gotceitas et al. 1999) due to cooler water temperatures and diminished prey fields (Shuter and Post 1990; Schultz and Conover 1999; Hurst and Conover 2001).

\footnotetext{
* Corresponding author: andrebuc@vims.edu
}

Received April 19, 2005; accepted February 6, 2006 Published online June 26, 2006
Large fish often have higher rates of survival than do smaller individuals, owing to a decreased vulnerability to predation and a greater energy storage capability that can be relied on as growth and foraging opportunities decrease during the winter (Sogard 1997). Large body size also results in a reduced weight-specific metabolic rate, which lowers the rate of depletion of stored energy. However, size-selective mortality does not occur for all species in temperate waters (Sogard 1997), presumably due to the complex interactions between water temperature, prey availability, and predation (Garvey et al. 1998).

For age-0 walleye pollock Theragra chalcogramma, survival was positively related to body size when fish were held without food in low-temperature conditions in the laboratory (Sogard and Olla 2000). Thus, accumulation of sufficient energy reserves and attainment of a relatively large body size before winter may be an important factor in walleye pollock winter 
survival and recruitment. Also, the ability of these fish to cope with deleterious overwinter conditions in the wild may vary geographically due to spatial differences in the size, growth, and diet of age-0 individuals (Paul et al. 1998b; Wilson 2000; Wilson et al. 2005). Much research has focused on the factors influencing the recruitment of walleye pollock into the adult population (Kendall et al. 1996), and the juvenile stage of development has been shown to be important (Bailey 2000). However, few studies have investigated how winter affects juvenile condition and energetics, and in this regard little is known about the relatively large population in the western Gulf of Alaska (GOA).

Therefore, the objective of this study was to examine the seasonal and geographic variation in body length and condition that exists within a cohort of juvenile walleye pollock before, during, and after its first winter in the western GOA. Two indices of body condition were used: (1) length-specific weight (Cone 1989; Patterson 1992) and (2) length-specific whole-body energy content (WBEC; Paul et al. 1998a; Foy and Paul 1999). Comparison of these two condition indices was an ancillary objective to explore the suitability of using at-sea measurements of fish length and weight as proxies for WBEC, which is more difficult to obtain.

\section{Methods}

Field collection.-Juvenile (ages 0-1) walleye pollock of the 2000 year-class were sampled along the continental shelf of the western GOA between $151^{\circ}$ and $161^{\circ} \mathrm{W}$ longitude (Figure 1). The study area was divided into three regions (Kodiak, Semidi, and Shumagin) similar to those used by Wilson (2000) and Brown and Bailey (1992). The 2000 year-class was sampled during four different time periods: AugustSeptember of 2000 (Aut00); January-March of 2001 (Win01); June-July of 2001 (Sum01); and AugustSeptember of 2001 (Aut01) (Table 1).

Samples were obtained during various groundfish assessment and research cruises conducted by the National Marine Fisheries Service (NMFS) and the University of Alaska (Table 1). Trawls were equipped with small-mesh cod end liners and were fished mainly during daylight hours. In Aut00, age-0 members of the 2000 year-class were distinguished from older individuals based on a clear break in the size-frequency distribution (Brodeur and Wilson 1996). After the yearclass reached age 1 (Win01-Aut01), the upper size limit of the cohort was estimated based on NMFS length-at-age data (M. Dorn, Alaska Fisheries Science Center, unpublished data). Up to 150 individuals from each trawl catch were randomly selected and frozen at $-20^{\circ} \mathrm{C}$ for subsequent analysis in the laboratory.

Water temperature was measured at each sampling location by use of a calibrated SBE-19, SBE-39 (SeaBird Electronics), or microbathythermograph (Richard Brancker Research, Ltd.). Temperature profiles were averaged for all stations by season and region.

Laboratory analysis.-In the laboratory, frozen samples were thawed in seawater within 2-31 months after collection. An average of 13 fish (range $=1-49$ ) were selected from each station to represent the available size range. Standard length (SL) was measured to the nearest millimeter. Whole-body weight was measured to the nearest milligram after fish were blotted dry. All length and weight measurements were corrected for preservation effects by use of shrinkage conversion equations (Buchheister and Wilson 2005). No correction was applied to account for differences in the length of time samples were frozen because Buchheister and Wilson (2005) demonstrated that preservation durations of 1.5-27 months did not significantly affect length reduction or weight loss in walleye pollock.

We determined WBEC for a total of 168 fish. These samples were obtained from a minimum of two stations within each season-region combination (Figure 1). Fish were selected to represent the available size range. Individuals were measured, weighed, and then dried whole at $65^{\circ} \mathrm{C}$ until a constant weight was attained. Fish $(n=134)$ were homogenized and pelletized $(0.03-$ $0.17 \mathrm{~g}$ dry weight), and the energy density $(\mathrm{kJ} / \mathrm{g}$ dry weight) of each fish was measured with a Parr 1425 Semimicro bomb calorimeter. The mean difference in energy density measurements between replicate pellets from 41 fish was low (1.7\%), and values were highly concordant (concordance correlation coefficient $\left[r_{c}\right]=$ 0.95; Zar 1999); therefore, subsequent energy determinations were based on one pellet per fish. Energy densities were converted to kilojoules per gram wet weight based on the ratio of dry weight to wet weight for each individual.

A freezer failure spoiled many of the Kodiak WBEC samples collected during Sum01 and Aut01. We therefore include energy density data $(n=34)$ from a proximate analysis of age- 1 walleye pollock collected from the corresponding region and seasons by researchers on the FV Alaska Beauty (Table 1; R.J.F., unpublished data). For determination of proximate composition, frozen samples were ground into a homogenate and lipid was extracted by means of the supercritical fluid extraction method in a LECO FA100 Fat Analyzer. Protein content was determined with a LECO FP-2000 Nitrogen Analyzer, whereas ash content was determined by combustion of homogenate in a muffle furnace at $510^{\circ} \mathrm{C}$ until a constant weight was attained. Proximate composition estimates were converted to energy density based on conversions of $36.43 \mathrm{~kJ} / \mathrm{g}$ for lipid and $20.10 \mathrm{~kJ} / \mathrm{g}$ for protein (Brett 


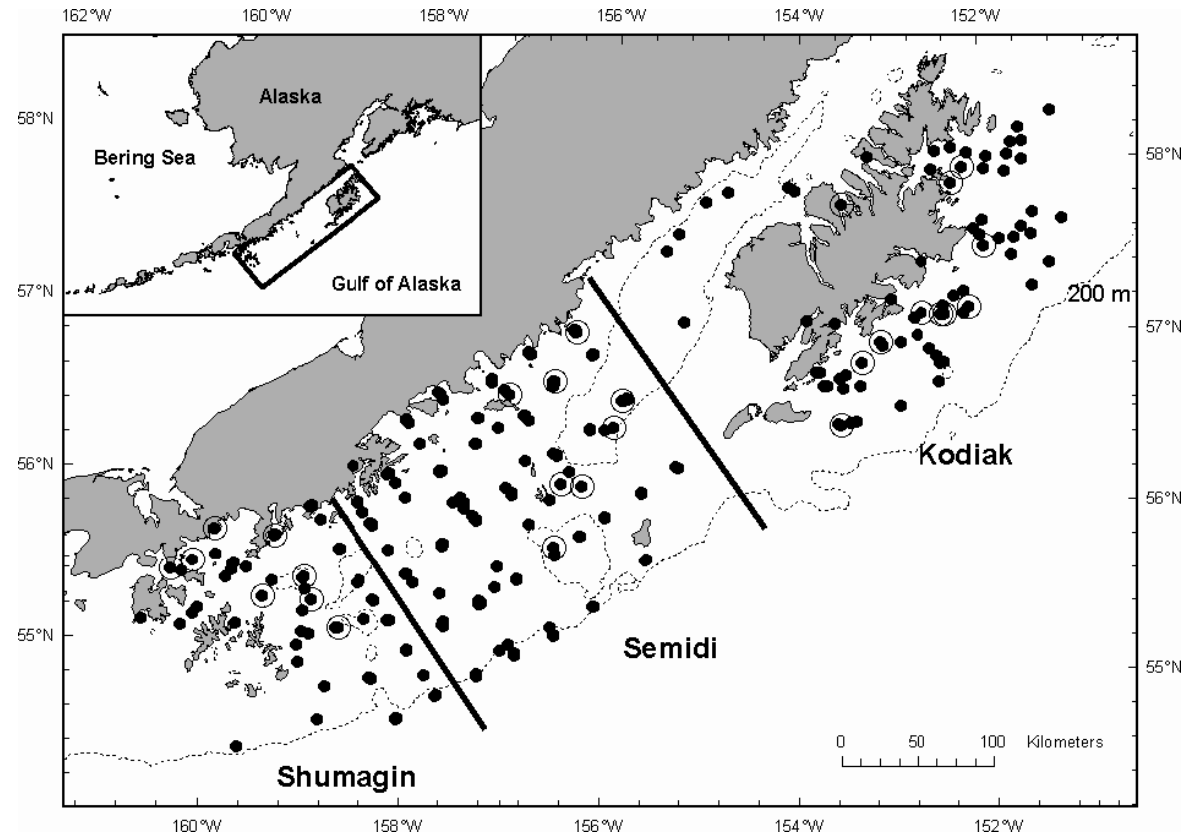

FIGURE 1.- Study area and locations of the Kodiak, Semidi, and Shumagin regions in the Gulf of Alaska, where walleye pollock of the 2000 year-class were sampled as age-0-1 juveniles during autumn 2000-autumn 2001. Length and weight data were collected from juveniles sampled at all locations (filled circles), and whole-body energy content was measured in juveniles from a subset of the stations (larger open circles).

1995); these conversions have been shown to yield similar results to values obtained by bomb calorimetry (Vollenweider 2004). Stomach contents were removed from fish used in proximate composition analyses.

Analysis of body length and condition.-Temporal and regional differences in SL were examined by plotting mean SL per station against date of sampling. Data from this study were compared graphically with a polynomial regression model of NMFS groundfish survey data (1973-1992) published by Brodeur and Wilson (1996). Coefficients for their regression model were converted to the appropriate length type (SL) by means of length conversion equations (Buchheister and Wilson 2005). Where appropriate, we used analysis of variance (ANOVA) to test for regional differences in mean length for each season.

Analysis of covariance (ANCOVA) was used to test for seasonal and regional differences in both lengthweight and length-WBEC relationships. For each ANCOVA, length was the covariate, while season and region were the main effects. Before testing seasonal and regional effects, we first confirmed a lack

TABLE 1.- Sampling information for collection of juvenile walleye pollock from the western Gulf of Alaska. Fishing gears are as follows: Marinovich midwater trawl (MMT), Aleutian wing 30/26 trawl (AWT), modified Stauffer midwater trawl (MSMT), high-opening shrimp trawl (HST), poly-nor'eastern bottom trawl (POLYNE), and Bering billionaire midwater trawl (BBMT).

\begin{tabular}{clllll}
\hline \multicolumn{1}{c}{ Season } & Vessel name & \multicolumn{1}{c}{ Regions sampled } & Start date & End date & Gear \\
\hline \multirow{2}{*}{ Autumn 2000 } & Miller Freeman & Kodiak & 12 Aug & 19 Aug & MMT, AWT \\
& Miller Freeman & Kodiak, Semidi, Shumagin & 3 Sep & 19 Sep & MSMT, HST \\
Winter 2001 & Miller Freeman & Kodiak, Semidi & 31 Jan & 2 Feb & POLYNE \\
& Sea Storm & Kodiak & 11 Feb & 28 Feb & POLYNE \\
& Miller Freeman & Shumagin & 14 Feb & 18 Feb & POLYNE, AWT \\
& Ocean Harvester & Shumagin & 8 Mar & 12 Mar & POLYNE \\
& Miller Freeman & Kodiak, Semidi & 13 Mar & 26 Mar & POLYNE, AWT \\
Summer 2001 & Vesteraalen & Kodiak, Semidi, Shumagin & 2 Jun & 8 Jul & POLYNE \\
& Morning Star & Kodiak, Semidi, Shumagin & 8 Jun & 20 Jul & POLYNE \\
Alaska Beauty & Kodiak & 25 Jul & 31 Jul & BBMT \\
& Miller Freeman & Kodiak, Semidi, Shumagin & 3 Sep & 18 Sep & MSMT, HST \\
& Alaska Beauty & Kodiak & 11 Sep & 13 Sep & BBMT \\
\hline
\end{tabular}


of significant differences between regression slopes. We then examined differences in length-specific weight (or length-specific WBEC) by testing for differences in $y$-intercepts. Any significant season or region effects in the ANCOVA models were followed by pairwise comparison tests between pairs of consecutive seasons or among the three regions. Critical $P$-values were Bonferroni-corrected for the number of comparisons. For pairwise comparisons, relative differences between values were also calculated as percentages.

There were a few methodological differences in the ANCOVAs of the length-weight and WBEC data. $\log _{e}$ transformations were used to linearize the lengthweight relationships and homogenize their variances, but no transformation was necessary for the WBEC data. The length-weight ANCOVA had a split-plot design to account for the nesting of trawl haul (the sampling unit) within season and region (Milliken and Johnson 1992). However, owing to small sample sizes, the ANCOVA for WBEC did not incorporate a nested design. Also, only stations with four or more fish were used in the length-weight analysis.

Correlation analysis of condition indices.-Correlation analysis of residual WBEC and residual weight (WT) was conducted to determine whether individuals that were relatively heavy for their length were also relatively energy rich. Residuals were calculated by use of linear least-squares regressions fit to all data pooled. The WT residuals were based on $\log _{e}$ transformed data. Only the 168 fish with both WBEC and length-weight data were used. Following Suthers et al. (1992), the significance of the correlation was based on the Bartlett chi-square test.

\section{Results}

Water temperature at all sampling stations ranged from $4^{\circ} \mathrm{C}$ to $12^{\circ} \mathrm{C}$. There was a pronounced seasonal signal in thermal structure that was similar among regions (Figure 2). Stratification in the water column was most notable in the autumn (Aut00 and Aut01); mean surface and bottom waters were near $11^{\circ} \mathrm{C}$ and $5^{\circ} \mathrm{C}$, respectively. During winter, the water column was uniform and well mixed and had a mean temperature of about $5^{\circ} \mathrm{C}$. Stratification was again evident in the summer with generally cooler temperatures relative to autumn. However, summer water temperatures in the Kodiak region were warmer and more similar to those in autumn; this result was probably attributable to the later sampling dates.

\section{Body Length}

A total of 2,241 walleye pollock from the 2000 yearclass were measured. Fresh SLs ranged from 39 to 263 mm (Table 2). Seasonal progression of mean length corresponded well with NMFS data from 1973 to 1992 (Figure 3). The seasonal rate of increase in length was rapid in Aut00, slowed to practically no increase by Win01, and then increased through Sum01 and Aut01.

Regional differences in fish length were also evident, particularly in the winter and summer (Figure 3). In Win01, the size of fish from the Kodiak region was significantly different from that of fish from the other regions combined (ANOVA: $P<0.001$ ); Kodiak fish were larger by an average of $18 \mathrm{~mm}$. Likewise, fish from the Kodiak region had larger mean lengths in Sum01, although this was confounded by later sampling dates. However, an average growth rate of $1.6 \mathrm{~mm} / \mathrm{d}$ would be required for fish from the Semidi and Shumagin regions to attain the same length as fish from the Kodiak region; realistic growth rates are typically below $1 \mathrm{~mm} / \mathrm{d}$ (Brodeur and Wilson 1996). Temporal differences in sampling and a possible bias in gear selectivity (Table 1) prevented the use of ANOVA for Aut00, although Kodiak fish appeared to have larger mean lengths on a given date than fish from other regions (Figure 3). Patterns in Aut01 could not be determined due to insufficient sampling.

\section{Body Condition}

Whole-body wet weight was determined for all 2,241 individuals that were measured for length. Fresh weights ranged from 0.5 to $173 \mathrm{~g}$. Coefficients of determination were high for most regressions of length-weight data, except in the Kodiak region in Aut01 (Table 2). Slope heterogeneity among seasons $(P=0.031)$ prevented the simultaneous analysis of all seasons and regions in one all-inclusive ANCOVA test. Therefore, the season effect was tested for each region individually, and likewise the region effect was tested for each season individually. In each of these resultant length-weight ANCOVA models, slopes of regressions were not significantly different (Tables 2,3 ), except for the test of season in the Semidi region $(P=0.011$; Table 3). Consequently, pairwise tests for seasonal differences were conducted for the Semidi region, omitting the comparisons of nonconsecutive seasons that were not of interest.

In all three regions, length-specific weight was significantly lower during winter than during other seasons (Table 3; Figure 4). Length-specific weight decreased significantly from Aut00 to Win01 by as much as $17.3 \%$ but subsequently rebounded by up to $19.8 \%$ in Sum01. Fish from the Semidi region also exhibited a significant increase of $11.4 \%$ from Sum01 to Aut01, but this was not observed in the other regions.

Significant regional differences in length-specific 

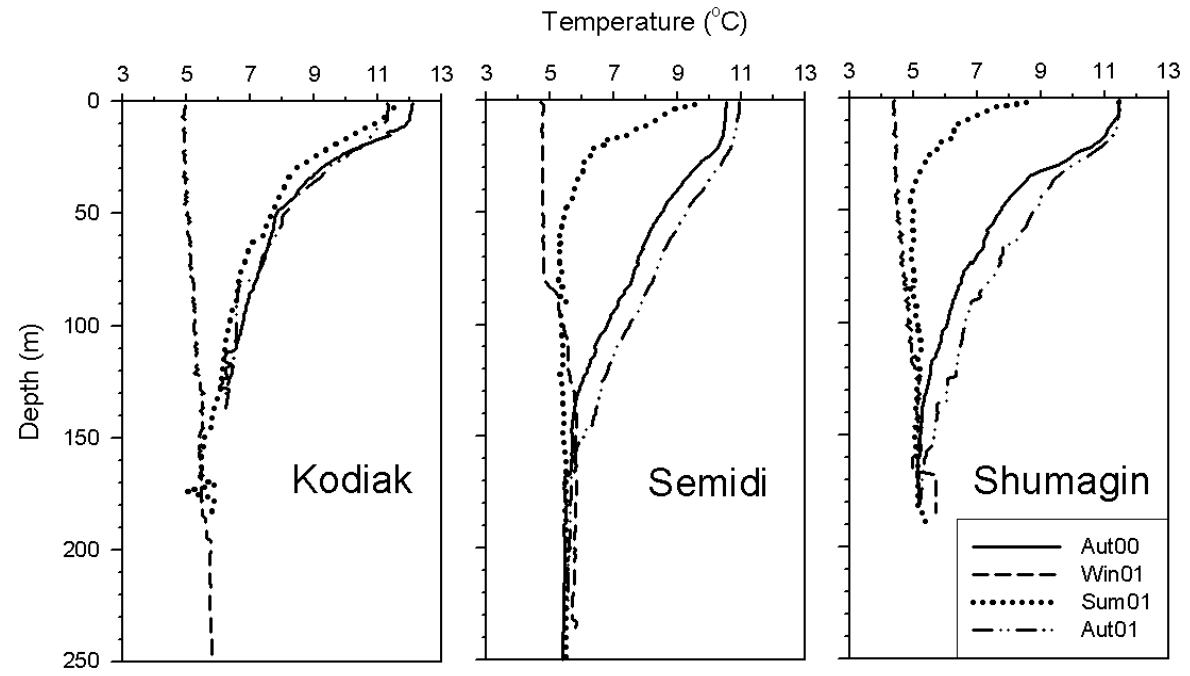

FIGURE 2.-Average seasonal temperature profile at walleye pollock collection locations in the Kodiak, Semidi, and Shumagin regions of the Gulf of Alaska through four time periods (autumn 2000 [Aut00], winter 2001 [Win01], summer 2001 [Sum01], and autumn 2001 [Aut01]).

weight were only detected during Aut00, and fish from the Kodiak region weighed nearly $6 \%$ more than similarly sized fish from the Semidi region (Table 4). Although not significant, Kodiak fish also had a tendency towards greater length-specific weight in Win01. No regional differences in weight at length were detected in Sum01 and Aut01.

The WBEC of juvenile walleye pollock ranged from 3.00 to $6.37 \mathrm{~kJ} / \mathrm{g}$ (Figure 5). In the ANCOVA for WBEC versus SL, slopes were not significantly different among regions or seasons; thus, a commonslope model was used. Both the seasonal and regional effects were found to be significant $(P=0.002$ and $P=$ 0.007 , respectively). Although the effect of the covariate (SL) was marginally nonsignificant $(P=$ 0.072), it was retained in the model because of its significant effect on WBEC over the entire data set $(P$ $<0.001 ;$ WBEC $=0.009[\mathrm{SL}]+3.070 ; r^{2}=0.372, n=$ 168).

Post hoc multiple-comparison tests of length-specific WBEC identified three significant differences between season pairs (Table 5; Figure 5). First, length-specific WBEC decreased from Aut00 to Win01 in the Semidi region $(0.584 \mathrm{~kJ} / \mathrm{g} ; 14.0 \%)$. Second, length-specific energy density of Shumagin fish increased by $0.861 \mathrm{~kJ} /$ $\mathrm{g}(23.1 \%)$ from Win01 to Sum01. Lastly, WBEC in the Kodiak region increased significantly by $0.574 \mathrm{~kJ} / \mathrm{g}$ (11.4\%) from Sum01 to Aut01. Thus, the seasonal

TABLE 2.-Least-squares linear regressions of $\log _{e}$ transformed juvenile walleye pollock standard length (SL; mm) and log transformed whole-body wet weight (WT; g) by region and season. The coefficient of determination $\left(r^{2}\right)$, number of fish (number of stations in parentheses), standard error of estimate of the regression (SEE), and range of standard lengths for each regression are also included $($ Aut00 = autumn 2000; Win01 = winter 2001; Sum01 = summer 2001; Aut01 = autumn 2001).

\begin{tabular}{|c|c|c|c|c|c|c|}
\hline Region & Season & Equation & $r^{2}$ & $N$ & $\mathrm{SEE}^{\mathrm{a}}$ & SL range \\
\hline \multirow[t]{4}{*}{ Kodiak } & Aut00 & $\log _{e}(\mathrm{WT})=3.136 \log _{e}(\mathrm{SL})-12.207$ & 0.968 & $103(8)$ & 0.057 & $59-102$ \\
\hline & Win01 & $\log _{e}(\mathrm{WT})=3.029 \log _{e}(\mathrm{SL})-11.907$ & 0.960 & $200(23)$ & 0.070 & $90-161$ \\
\hline & Sum01 & $\log _{e}(\mathrm{WT})=3.307 \log _{e}(\mathrm{SL})-13.124$ & 0.909 & $112(14)$ & 0.077 & $138-194$ \\
\hline & Aut01 & $\log _{e}(\mathrm{WT})=2.956 \log _{e}(\mathrm{SL})-11.299$ & 0.548 & $31(4)$ & 0.152 & $174-228$ \\
\hline \multirow[t]{4}{*}{ Semidi } & Aut00 & $\log _{e}(\mathrm{WT})=3.151 \log _{e}(\mathrm{SL})-12.330$ & 0.986 & $810(48)$ & 0.064 & $39-111$ \\
\hline & Win01 & $\log _{e}(\mathrm{WT})=3.169 \log _{e}(\mathrm{SL})-12.607$ & 0.974 & $60(4)$ & 0.063 & $85-138$ \\
\hline & Sum01 & $\log _{e}(\mathrm{WT})=2.958 \log _{e}(\mathrm{SL})-11.485$ & 0.957 & $50(5)$ & 0.062 & $98-148$ \\
\hline & Aut01 & $\log _{e}(\mathrm{WT})=3.003 \log _{e}(\mathrm{SL})-11.577$ & 0.977 & $227(26)$ & 0.068 & $128-263$ \\
\hline \multirow[t]{4}{*}{ Shumagin } & Aut00 & $\log _{e}(\mathrm{WT})=3.062 \log _{e}(\mathrm{SL})-11.944$ & 0.980 & $337(16)$ & 0.059 & $45-88$ \\
\hline & Win01 & $\log _{e}(\mathrm{WT})=3.046 \log _{e}(\mathrm{SL})-12.036$ & 0.947 & $126(15)$ & 0.090 & $75-156$ \\
\hline & Sum01 & $\log _{e}(\mathrm{WT})=3.177 \log _{e}(\mathrm{SL})-12.503$ & 0.925 & $67(7)$ & 0.090 & $92-152$ \\
\hline & Aut01 & $\log _{e}(\mathrm{WT})=3.132 \log _{e}(\mathrm{SL})-12.274$ & 0.971 & $118(7)$ & 0.071 & $130-236$ \\
\hline
\end{tabular}

${ }^{\text {a }}$ SEEs are reported for accurate back-calculation of untransformed length-weight relationships (Sprugel 1983). 


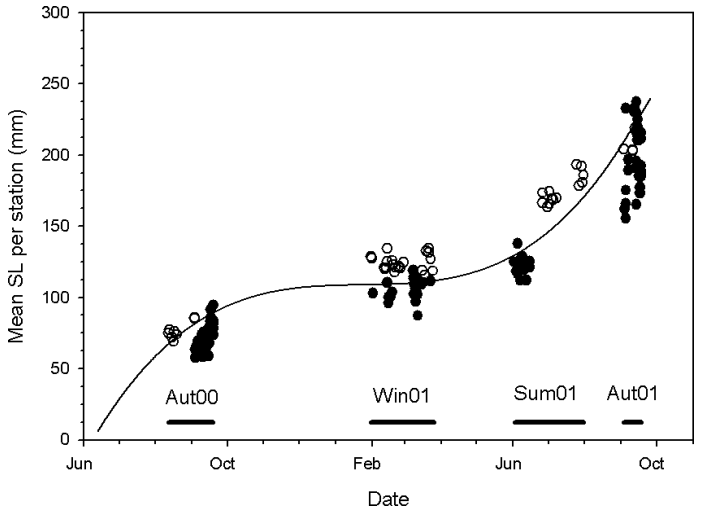

Figure 3.-Mean standard length (SL) of juvenile walleye pollock sampled at different stations in the Gulf of Alaska during different periods (see Figure 2 for period abbreviations). Open circles represent stations in the Kodiak region, filled circles stations from the Semidi and Shumagin regions. The third-order polynomial line was adapted from 1973-1992 National Marine Fisheries Service length data for walleye pollock (Brodeur and Wilson 1996).

effect was not consistent among regions, but two of the three significant differences involved relatively low wintertime energy density estimates.

The post hoc tests also detected three significant regional differences in length-specific WBEC (Table 6; Figure 5). In Aut00, fish from the Kodiak region exhibited length-specific energy densities that were $0.783-\mathrm{kJ} / \mathrm{g}(18.3 \%)$ higher than those of fish from the Shumagin region. During winter, the length-specific WBEC for Kodiak fish was significantly greater than that of fish from the Semidi region (by $0.607 \mathrm{~kJ} / \mathrm{g}$; $14.1 \%)$. During Sum01, length-specific energy densi- ties were high in the Shumagin region; average values were over $0.8 \mathrm{~kJ} / \mathrm{g}(17.6 \%)$ greater in the Shumagin region than in the Semidi region. Although the regional effect was not consistent among seasons, two of the three significant differences involved relatively high energy density estimates for fish from the Kodiak region.

\section{Comparison between Condition Indices}

The correlation between residual WBEC and residual WT was significant $(r=0.464, P<0.001)$. However, although energy density residuals tended to increase with weight residuals, the correlation was weak and WT residuals did not explain a large amount of the variance (Figure 6). We did note, however, that percent dry weight (DW) was a reasonably good predictor of energy density $($ WBEC $=0.314[\mathrm{DW}]-$ $\left.2.125 ; r^{2}=0.872, n=168\right)$.

\section{Discussion}

Seasonal variation in the length of juvenile walleye pollock was consistent with the patterns previously described by Brodeur and Wilson (1996). Our results indicate that the period of negligible increase in length during winter coincided with reduced water temperature in the upper $150 \mathrm{~m}$ of water. However, Brodeur and Wilson (1996) also showed that juvenile walleye pollock move into deeper water during winter. The regional pattern whereby juveniles are relatively large near Kodiak Island is also supported by previous work on age-0 walleye pollock (Wilson 2000). We recognize, however, the likelihood of bias in our fish size estimates due to the difficulty of sampling a cohort of individuals that grew and shifted vertically in the water

TABLE 3.- Summary results of ANCOVA tests of pairwise seasonal differences in walleye pollock length-weight relationships for three regions in the Gulf of Alaska. Differences among slopes and $y$-intercepts were tested at critical $(P)$ values of 0.017 and 0.005 , respectively (Bonferroni corrected; $\alpha=0.05$ ) and $P$-values are presented. Significance is indicated by bold italics. For each comparison, the season with the greater $y$-intercept, or length-specific weight, is included. Percent changes in length-specific weight from the earlier to the later season were calculated from back-transformed weights (Aut00=autumn 2000; Win01 = winter 2001; Sum01 = summer 2001; Aut01 = autumn 2001).

\begin{tabular}{|c|c|c|c|c|c|}
\hline \multirow[b]{2}{*}{ Region } & \multirow[b]{2}{*}{ Seasonal comparison } & \multicolumn{2}{|c|}{ Null hypothesis } & \multirow[b]{2}{*}{ Greater $y$-intercept } & \multirow[b]{2}{*}{$\%$ Change } \\
\hline & & Equal slopes & Equal intercepts & & \\
\hline \multirow[t]{4}{*}{ Kodiak } & All seasons & 0.209 & $<0.001$ & & \\
\hline & Aut00 vs/ Win01 & & $<0.001$ & Aut00 & -16.5 \\
\hline & Win01 vs. Sum01 & & $<0.001$ & Sum01 & 19.8 \\
\hline & Sum01 vs. Aut01 & & 0.181 & & \\
\hline \multirow[t]{4}{*}{ Semidi } & All seasons & 0.011 & & & \\
\hline & Aut00 vs. Win01 & 0.920 & $<0.001$ & Aut00 & -17.3 \\
\hline & Win01 vs. Sum01 & 0.120 & 0.001 & Sum01 & 13.4 \\
\hline & Sum01 vs. Aut01 & 0.500 & 0.002 & Aut01 & 11.4 \\
\hline \multirow[t]{4}{*}{ Shumagin } & All seasons & 0.254 & $<0.001$ & & \\
\hline & Aut00 vs. Win01 & & $<0.001$ & Aut00 & -16.2 \\
\hline & Win01 vs. Sum01 & & $<0.001$ & Sum01 & 16.9 \\
\hline & Sum01 vs. Aut01 & & 0.110 & Aut01 & \\
\hline
\end{tabular}




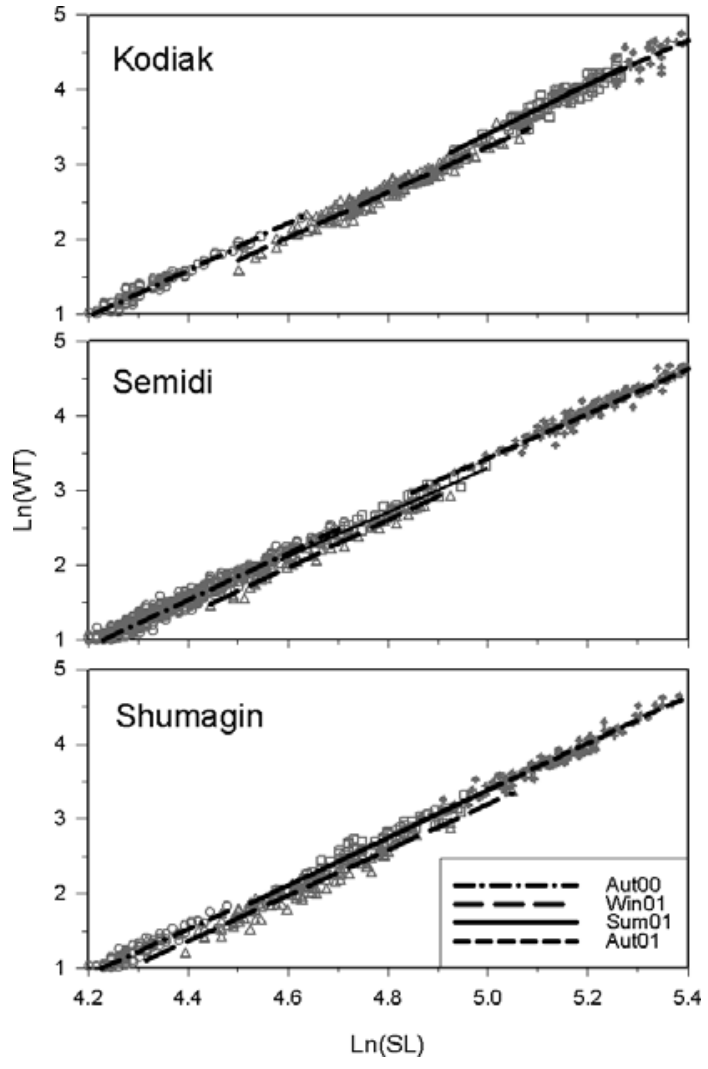

FIGURE 4.- - Least-squares linear regressions of $\log _{e}$ transformed weight (WT) on $\log _{e}$ transformed standard length (SL) of age-0-1 walleye pollock collected in the Gulf of Alaska during different periods (see Figure 2 for period abbreviations). Data are plotted separately for the Kodiak, Semidi, and Shumagin regions.

column. Nevertheless, it appears that as age- $0-1$ individuals our chosen cohort of walleye pollock was not atypical with regard to seasonal and geographic patterns in body length.

Seasonal reduction in body condition during winter has been shown for many species (Pulliainen and Korhonen 1990; Fechhelm et al. 1995; Jonas et al. 1996). In this study, length-specific weight decreased significantly in winter but recovered rapidly (up to $19.8 \%$ ) by summer. It can, however, be difficult to interpret such wintertime reductions in terms of survival. A laboratory study of age- 0 walleye pollock that were fasted for $205 \mathrm{~d}$ at temperatures below $2.5^{\circ} \mathrm{C}$ revealed that survivors experienced a mean weight loss of $22.8 \%$, while the mean weight loss for mortalities was $33.2 \%$ (Sogard and Olla 2000). Given the 4-7 months that elapsed between the Aut00 and Win01 samplings, the mean length-specific weight reductions (16-17\%) exhibited by the fish in this study through winter are reasonable. However, for these seasonal changes in length-specific weight to equate directly to the mean individual weight loss, growth in length would have to be zero for individual fish as the weight was lost. Consequently, percent changes in lengthspecific weight could be considered a high-end estimation of an individual's weight loss because the fish did increase in length between autumn and winter (Figure 2).

With regard to seasonal patterns in WBEC, Vollenweider (2004) and Paul et al. (1998b) reported similar energy density values for juvenile walleye pollock (3.0-5.0 kJ/g wet weight) in southeastern Alaska and Prince William Sound (PWS), respectively. Vollenweider (2004) witnessed yearly lows in WBEC for age0 and juvenile walleye pollock in March, dropping from highs recorded in December. On the other hand, the WBEC for PWS fish could be either significantly higher or lower in March than in the previous October depending on the year sampled (Paul et al. 1998b). This variation among studies and the fact that seasonal changes in WBEC continued to vary by region after winter suggest that fish energy densities may be more strongly influenced by localized environmental factors than by large-scale temporal changes. Although some species depend on stored energy for winter survival (Paul et al. 1993, 1998a; Jonas et al. 1996; Foy and Paul 1999), a heavy reliance on energy reserves in all regions was not evident in this study since decreases in length-specific WBEC were not always detected. However, dependence on stored energy may occur to a more substantial extent at smaller regional scales, as in the Semidi region.

In our study, significant spatial heterogeneity in juvenile walleye pollock condition was detected within seasons, which was also shown for walleye pollock in PWS (Paul et al. 1998b). Although not always consistent among measures of condition or among seasons, there was a general trend for fish from the Kodiak region to be relatively large, heavy, or energy rich, particularly during Aut00 and Win01. By Sum01 and Aut01, length-specific weights and energy densities of fish from the different regions generally converged, suggesting that the relative advantage in condition of Kodiak fish may disappear after winter, although body length may still be greater. Improved condition of walleye pollock near Kodiak Island has been supported by other studies showing that juvenile body length and growth rates in this region were higher than those in other areas to the southwest (Brown and Bailey 1992; Wilson 2000).

Variability in feeding may be one of the major factors contributing to seasonal and regional differences in juvenile condition. Juvenile walleye pollock 
TABLE 4.-Summary results of ANCOVA tests of regional differences in walleye pollock length-weight relationships by season for three regions in the Gulf of Alaska. Differences among slopes and $y$-intercepts were tested at critical $(P)$ values of 0.013 and 0.005 , respectively (Bonferroni corrected; $\alpha=0.05$ ) and $P$-values are presented. Bold italics indicate significance. For each comparison, the region with the greater $y$-intercept is included. Percent differences between the regional length-specific weights were calculated from back-transformed values.

\begin{tabular}{|c|c|c|c|c|c|}
\hline \multirow[b]{2}{*}{ Season } & \multirow[b]{2}{*}{ Regional comparison } & \multicolumn{2}{|c|}{ Null hypothesis } & \multirow[b]{2}{*}{ Greater $y$-intercept } & \multirow[b]{2}{*}{$\%$ Difference } \\
\hline & & Equal slopes & Equal intercepts & & \\
\hline \multirow{4}{*}{ Autumn 2000} & All regions & 0.022 & 0.001 & & \\
\hline & Kodiak vs. Semidi & & 0.001 & Kodiak & 5.9 \\
\hline & Kodiak vs. Shumagin & & 0.031 & Kodiak & 4.0 \\
\hline & Semidi vs. Shumagin & & 0.073 & Shumagin & 1.8 \\
\hline \multirow[t]{4}{*}{ Winter 2001} & All regions & 0.444 & 0.046 & & \\
\hline & Kodiak vs. Semidi & & 0.074 & Kodiak & 4.8 \\
\hline & Kodiak vs. Shumagin & & 0.019 & Kodiak & 5.7 \\
\hline & Semidi vs. Shumagin & & 0.733 & & \\
\hline Summer 2001 & All regions & 0.120 & 0.340 & & \\
\hline Autumn 2001 & All regions & 0.751 & 0.671 & & \\
\hline
\end{tabular}

probably feed during their first winter; length-specific weight losses from Aut00 to Win01 were less than weight losses experienced by experimentally starved juveniles (Sogard and Olla 2000), and there was a lack of substantial accumulation of stored energy before the winter in some regions. However, feeding in winter probably occurs at a reduced rate, as indicated by continued reduction in length-specific weight from Aut00 to Win01. Also, the abundance of many of the zooplankton species that are important in the diets of juvenile walleye pollock declines during winter in the northern GOA (Brodeur and Wilson 1996; Incze et al. 1997; Foy and Paul 1999; Coyle and Pinchuk 2003). Regional variability in prey availability may also explain the generally higher fall and winter condition of fish in the Kodiak region, where greater proportions of euphausiids were found in the diets of age- 0 walleye pollock in autumn relative to those of other regions (Merati and Brodeur 1996). Such enhanced feeding conditions in the Kodiak region may persist through the winter, contributing to improved fish condition. Preliminary diet analyses support these conclusions; median stomach fullness decreased significantly from fall to winter in the Kodiak and Semidi regions, but median stomach fullness in winter was more than four times greater for fish from Kodiak than from the other regions (A.B., unpublished data).

Relative morphometric condition was not a robust indicator of relative energy density. Patterns in lengthspecific WBEC were not as clear as patterns in lengthspecific weight, and there was a lack of a strong relationship between the residuals of weight and WBEC. However, the significant differences detected for each measure of condition did not directly contradict one another, and they reflected the same general trends: low overall wintertime condition and higher condition of Kodiak fish. Length, weight, and
WBEC can provide valuable information on the growth allometry and energetic status of fish, but inferences regarding relative energy density should be made cautiously when based solely on length-specific weight.

One concern about the use of whole-body weight as an index of fish condition relates to the effect of stomach contents on weight and energy density. We found no evidence to indicate that removal of stomach contents would have altered our conclusions. Significant decreases in length-specific weight between Aut00 and Win01 were still detected when weights of stomach contents were subtracted from total fish weights in a concurrent study of walleye pollock diets in the Shumagin and Semidi regions (ANCOVA: $P=$ 0.004 and $P<0.001$, respectively). Furthermore, the median stomach fullness of walleye pollock was $0.7 \%$ of total body weight in Aut00 $(n=338$, range $=0$ $11.2 \%$; M.T.W., unpublished data) and $0.3 \%$ in the other seasons $(n=167$, range $=0-5.7 \%$; A.B., unpublished data). These relatively low stomach content weights would have negligible effects on both length-specific weight and WBEC. Also, any impact of prey items on WBEC would be further minimized by the similarity in energy density values of walleye pollock and their prey (A.B., unpublished data).

The use of energy density data determined from two different methods (bomb calorimetry and proximate composition analysis) was not ideal and may be the source of some error, but we deemed it justifiable. The comparability between WBEC measurements obtained by the two methods is dependent on the conversion factors used for lipids and proteins in the proximate analysis method (Craig et al. 1978). Although a direct comparison of methods was not possible in this study, the conversion factors used here (Brett 1995) were directly supported by Vollenweider's (2004) study of 

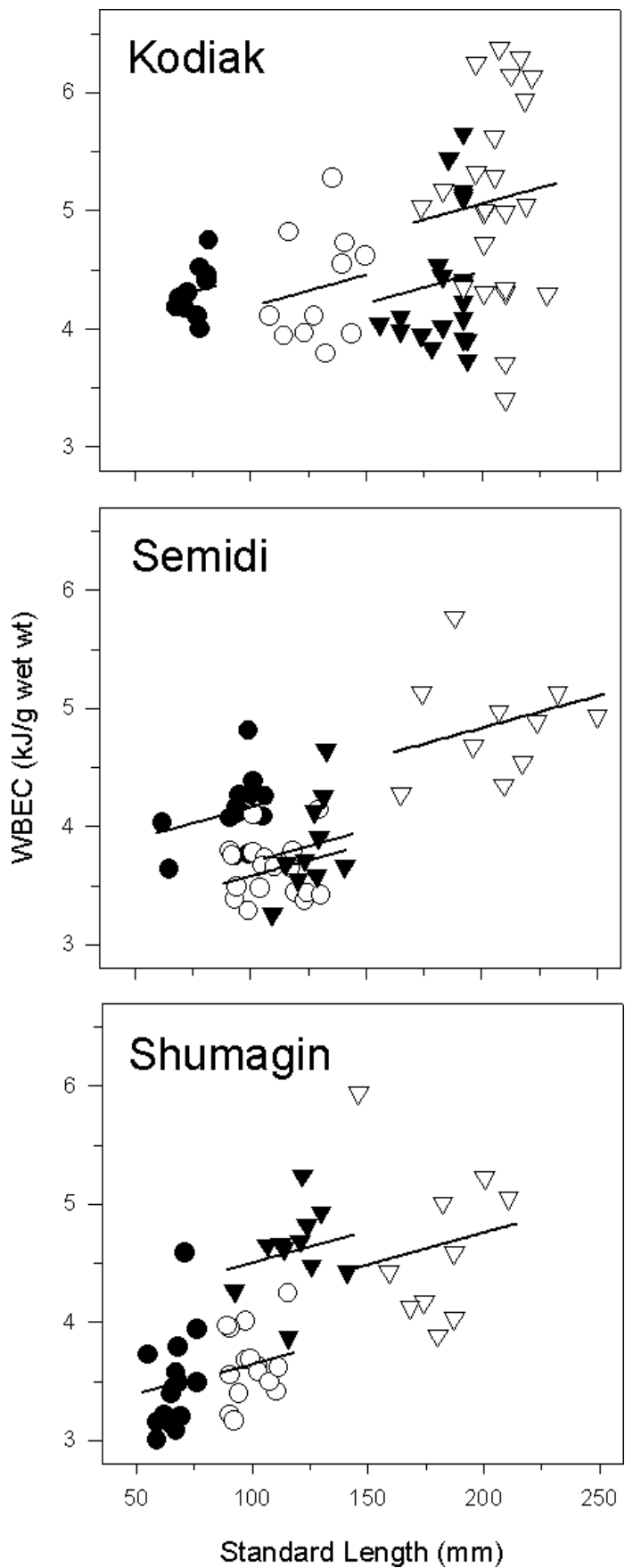

FIGURE 5.-Whole-body energy content (WBEC) versus standard length of individual age-0-1 walleye pollock collected in the Gulf of Alaska during autumn 2000 (filled circles), winter 2001 (open circles), summer 2001 (filled triangles), and autumn 2001 (open triangles). Data are plotted for fish from the Kodiak, Semidi, and Shumagin regions. The least-squares linear regressions were obtained from a common-slope ANCOVA model.
TABLE 5.- $P$-values for post hoc pairwise comparisons between seasons conducted after an ANCOVA of the wholebody energy content of walleye pollock in the Gulf of Alaska with standard length as the covariate. Differences between consecutive seasons were tested for each region at a critical value of 0.006 (Bonferroni corrected; $\alpha=0.05$ ). Bold italics indicate significant test results. See Table 2 for season abbreviations.

\begin{tabular}{lccc}
\hline Region & Aut00 vs. Win01 & Win01 vs. Sum01 & Sum01 vs. Aut01 \\
\hline Kodiak & 0.342 & $0.326^{\mathrm{a}}$ & $\mathbf{0 . 0 0 1}^{\mathrm{a}}$ \\
Semidi & $\mathbf{0 . 0 0 2}$ & 0.552 & 0.068 \\
Shumagin & 0.928 & $<\mathbf{0 . 0 0 1}$ & 0.312 \\
\hline
\end{tabular}

${ }^{a}$ Most of the energy density measurements for Sum01 and Aut01 in Kodiak were calculated from proximate composition rather than bomb calorimetry.

forage fish from southeastern Alaska. Also, only one of six significant comparisons involved the supplementary proximate composition data (Tables 5,6 ); thus, the major conclusions drawn from the analyses are not affected by the additional data set.

It can be difficult to separate fish size and seasonal effects on WBEC estimates because WBEC can be positively related to size for some species (Hislop et al. 1991; Paul et al. 1998a). In the Bering Sea, the energy density of age- 0 walleye pollock increased with fish size (Ciannelli et al. 2002), but no such relationship was detected among age- 0 walleye pollock in PWS (Paul et al. 1998b). In our analysis, despite marginal nonsignificance $(P=0.072)$, length was retained in the ANCOVA model to ensure that any detected differences in energy density could not be attributed to fish length. We considered this approach to be more conservative, and exclusion of length from the model did not alter our conclusions.

Several issues may confound the spatial and temporal patterns presented in this study. These include the residency or migratory habits of juveniles; different

TABLE 6.- $P$-values for post hoc pairwise comparisons between regions conducted after an ANCOVA of the wholebody energy content of walleye pollock in the Gulf of Alaska with standard length as the covariate. Differences between regions were tested for each season at a critical value of 0.004 (Bonferroni corrected; $\alpha=0.05$ ). Bold italics indicate significant test results. See Table 2 for season abbreviations.

\begin{tabular}{lccr}
\hline Season & $\begin{array}{c}\text { Kodiak vs. } \\
\text { Semidi }\end{array}$ & $\begin{array}{c}\text { Kodiak vs. } \\
\text { Shumagin }\end{array}$ & $\begin{array}{r}\text { Semidi vs. } \\
\text { Shumagin }\end{array}$ \\
\hline Aut00 & 0.191 & $<\mathbf{0 . 0 0 1}$ & 0.015 \\
Win01 & $\mathbf{0 . 0 0 2}$ & 0.013 & 0.716 \\
Sum01 & $0.338^{\mathrm{a}}$ & $0.040^{\mathrm{a}}$ & $<\mathbf{0 . 0 0 1}$ \\
Aut01 & $0.236^{\mathrm{a}}$ & $0.141^{\mathrm{a}}$ & 0.741 \\
\hline
\end{tabular}

${ }^{\mathrm{a}}$ Most of the energy density measurements for Sum01 and Aut01 in Kodiak were calculated from proximate composition rather than bomb calorimetry. 


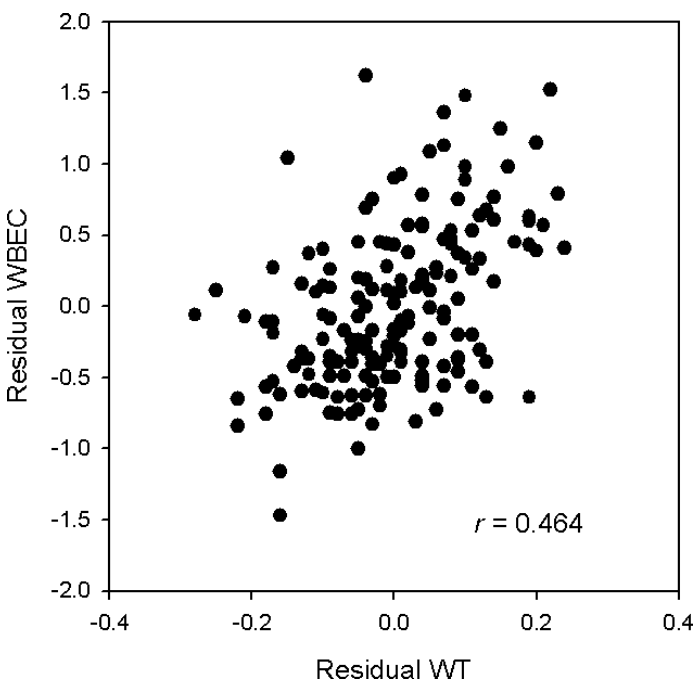

Figure 6.-Scatterplot and correlation $(r)$ of whole-body energy content (WBEC; kJ/g) and weight (WT; g) residuals for age-0-1 walleye pollock collected in the Gulf of Alaska during autumn 2000-autumn 2001.

spawning populations in each of the regions (Brown and Bailey 1992; Brodeur and Wilson 1996); differences in hatch date and local genetic adaptations; interannual variability in growth (Bailey et al. 1996) and WBEC (Paul et al. 1998b); variability in selective pressure by predation and population density; and depth of sampling in relation to seasonal vertical migration (Brodeur and Wilson 1996). Although the influence of these factors is unclear, it is evident that fish size and condition are neither geographically nor temporally homogenous.

Despite the seasonal and regional heterogeneity in condition of juvenile walleye pollock, the impact of such differences on overwinter mortality remains uncertain. Drastic reductions in length-specific weight are indicative of changes in growth allometry and may be a sign of overwinter stress, but energy density estimates did not support this in all areas. Also, the condition and size of fish from the Kodiak region appear to be generally greater than those of fish from the other regions, but whether this confers any survival advantage has yet to be determined. Our understanding of walleye pollock mortality, growth, and recruitment would probably benefit from direct examinations of overwinter mortality as well as descriptions of the factors mediating the observed differences in fish condition.

\section{Acknowledgments}

We are especially grateful to C. D. Wilson, M. S. Busby, N. Raring, L. L. Britt, M. A. Guttormsen, D.
Nichol, W. C. Flerx, J. W. Orr, M. H. Martin, P. G. Von Szalay, C. M. Jump, E. S. Brown, M. E. Wilkins, D. G. Kachel, and all cruise personnel from the Miller Freeman, Sea Storm, Ocean Harvester, Morning Star, Vesteraalen, and Alaska Beauty involved in the collection of samples and data. Statistical assistance from K. Mier and S. J. Picquelle was also greatly appreciated. J. Duffy-Anderson, K. M. Bailey, J. M. Napp, T. W. Buckley, and two anonymous reviewers provided constructive comments on earlier drafts of the manuscript. This research is contribution FOCI-L543 to the National Oceanic and Atmospheric Administration's Fisheries-Oceanography Coordinated Investigations and was supported by grants to M. T. Wilson from the Sea Lion Research Initiative (Grant 02FF-04) and the North Pacific Research Board (Grant R0308).

\section{References}

Bailey, K. M. 2000. Shifting control of recruitment of walleye pollock Theragra chalcogramma after a major climatic and ecosystem change. Marine Ecology Progress Series 198:215-224.

Bailey, K. M., A. L. Brown, M. M. Yoklavich, and K. L. Mier. 1996. Interannual variability in growth of larval and juvenile walleye pollock Theragra chalcogramma in the western Gulf of Alaska, 1983-91. Fisheries Oceanography 5(Supplement 1):137-147.

Brett, J. R. 1995. Energetics. Pages 3-68 in C. Groot, L. Margolis, and W. C. Clarke, editors. Physiological ecology of Pacific salmon. UBC Press, Vancouver.

Brodeur, R. D., and M. T. Wilson. 1996. A review of the distribution, ecology and population dynamics of age0 walleye pollock in the Gulf of Alaska. Fisheries Oceanography 5(Supplement 1):148-166.

Brown, A. L., and K. M. Bailey. 1992. Otolith analysis of juvenile walleye pollock Theragra chalcogramma from the western Gulf of Alaska. Marine Biology 112:23-30.

Buchheister, A., and M. T. Wilson. 2005. Shrinkage correction and length conversion equations for Theragra chalcogramma, Mallotus villosus, and Thaleichthys pacificus. Journal of Fish Biology 67:541-548.

Ciannelli, L., A. J. Paul, and R. D. Brodeur. 2002. Regional, interannual and size-related variation of age-0 year walleye pollock whole body energy content around the Pribilof Islands, Bering Sea. Journal of Fish Biology 60:1267-1279.

Cone, S. R. 1989. The need to reconsider the use of condition indices in fishery science. Transactions of the American Fisheries Society 118:510-514.

Coyle, K. O., and A. I. Pinchuk. 2003. Annual cycle of zooplankton abundance, biomass and production on the northern Gulf of Alaska shelf, October 1997 through October 2000. Fisheries Oceanography 12:327-338.

Craig, J. F., M. J. Kenley, and J. F. Talling. 1978. Comparative estimations of the energy content of fish tissue from bomb calorimetry, wet oxidation, and proximate analysis. Freshwater Biology 8:585-590.

Cushing, D. H. 1990. Plankton production and year-class strength in fish populations: an update of the match/ 
mismatch hypothesis. Advances in Marine Biology 26:249-293.

Fechhelm, R. G., W. B. Griffiths, W. J. Wilson, B. J. Gallaway, and J. D. Bryan. 1995. Intra- and interseasonal changes in the relative condition and proximate body composition of broad whitefish from the Prudhoe Bay region of Alaska. Transactions of the American Fisheries Society 124:508-519.

Foy, R. J., and A. J. Paul. 1999. Winter feeding and changes in somatic energy content of age-0 Pacific herring in Prince William Sound, Alaska. Transactions of the American Fisheries Society 128:1193-1200.

Garvey, J. E., R. A. Wright, and R. A. Stein. 1998. Overwinter growth and survival of age-0 largemouth bass (Micropterus salmoides): revisiting the role of body size. Canadian Journal of Fisheries and Aquatic Sciences 55:2414-2424.

Gotceitas, V., D. A. Methven, S. Fraser, and J. A. Brown. 1999. Effects of body size and food ration on over-winter survival and growth of age-0 Atlantic cod, Gadus morhua. Environmental Biology of Fishes 54:413-420.

Hislop, J. R. G., M. P. Harris, and J. G. M. Smith. 1991. Variation in the calorific value and total energy content of the lesser sandeel (Ammodytes marinus) and other fish preyed on by seabirds. Journal of Zoology 224:501-517.

Hurst, T. P., and D. O. Conover. 1998. Winter mortality of young-of-the-year Hudson River striped bass (Morone saxatilis): size-dependent patterns and effects on recruitment. Canadian Journal of Fisheries and Aquatic Sciences 55:1122-1130.

Hurst, T. P., and D. O. Conover. 2001. Diet and consumption rates of overwintering YOY striped bass, Morone saxatilis, in the Hudson River. Fishery Bulletin 99:545-553.

Incze, L. S., D. W. Siefert, and J. M. Napp. 1997. Mesozooplankton of Shelikof Strait, Alaska: abundance and community composition. Continental Shelf Research 17:287-305.

Jonas, J. L., C. E. Kraft, and T. L. Margenau. 1996. Assessment of seasonal changes in energy density and condition in age- 0 and age- 1 muskellunge. Transactions of the American Fisheries Society 125:203-210.

Kendall, A. W., J. D. Schumacher, and S. Kim. 1996. Walleye pollock recruitment in Shelikof Strait: applied fisheries oceanography. Fisheries Oceanography 5(Supplement 1):4-18

Merati, N., and R. D. Brodeur. 1996. Feeding habits and daily ration of juvenile walleye pollock, Theragra chalcogramma, in the western Gulf of Alaska. NOAA Technical Report NMFS 126:65-79.

Milliken, G. A., and D. E. Johnson. 1992. Analysis of messy data, volume I. Designed experiments. Chapman and Hall, London.

Patterson, K. R. 1992. An improved method for studying the condition of fish, with an example using Pacific sardine
Sardinops sagax (Jenyns). Journal of Fish Biology 40:821-831.

Paul, A. J., J. M. Paul, and R. L. Smith. 1993. The seasonal changes in somatic energy content of Gulf of Alaska yellowfin sole, Pleuronectes asper. Journal of Fish Biology 43:131-138.

Paul, A. J., J. M. Paul, and E. D. Brown. 1998a. Fall and spring somatic energy content for Alaskan Pacific herring (Clupea pallasi Valenciennes 1847) relative to age, size, and sex. Journal of Experimental Marine Biology and Ecology 223:133-142.

Paul, A. J., J. M. Paul, and R. L. Smith. 1998b. Seasonal changes in whole-body energy content and estimated consumption rates of age-0 Walleye Pollock from Prince William Sound, Alaska. Estuarine, Coastal, and Shelf Science 47:251-259.

Pitcher, T. J., and P. J. B. Hart. 1982. Fisheries Ecology. AVI, Westport, Connecticut.

Pulliainen, E., and K. Korhonen. 1990. Seasonal changes in condition indices in adult mature and non-maturing burbot, Lota lota (L.), in the northeastern Bothnian Bay, northern Finland. Journal of Fish Biology 36:251-259.

Schultz, E. T., and D. O. Conover. 1999. The allometry of energy reserve depletion: test of a mechanism for sizedependent winter mortality. Oecologia 119:474-483.

Shuter, B. J., and J. R. Post. 1990. Climate, population viability, and the zoogeography of temperate fishes. Transactions of the American Fisheries Society 119:314 336.

Sogard, S. M. 1997. Size-selective mortality in the juvenile stage of teleost fishes: a review. Bulletin of Marine Science 60:1129-1157.

Sogard, S. M., and B. L. Olla. 2000. Endurance of simulated winter conditions by age- 0 walleye pollock: effects of body size, water temperature, and energy stores. Journal of Fish Biology 56:1-21.

Sprugel, D. G. 1983. Correcting for bias in log-transformed allometric equations. Ecology 64:209-210.

Suthers, I. M., A. Fraser, and K. T. Frank. 1992. Comparison of lipid, otolith, and morphometric condition indices of pelagic juvenile cod Gadus morhua from the Canadian Atlantic. Marine Ecology Progress Series 84:31-40.

Vollenweider, J. J. 2004. Variability in Steller sea lion (Eumetopias jubatus) prey quality in southeaster Alaska. Master's thesis. University of Alaska, Fairbanks.

Wilson, M. T. 2000. Effects of year and region on the abundance and size of age-0 walleye pollock, Theragra chalcogramma, in the western Gulf of Alaska, 19851988. Fishery Bulletin 98:823-834.

Wilson, M. T., A. L. Brown, and K. L. Mier. 2005. Geographic variation among age-0 walleye pollock (Theragra chalcogramma): evidence of mesoscale variation in nursery quality? Fishery Bulletin 103:207-218.

Zar, J. H. 1999. Biostatistical analysis. Prentice Hall, Upper Saddle River, New Jersey. 